\section{Commentary: Is the cone a superior form?}

\author{
Emile Bacha, MD, FACS
}

In architecture, a triangle is considered a structurally sound form, and a cone-a 3-dimensional infinite triangle-distributes forces most efficiently. This is relevant to creating a durable surgical repair of an Ebstein's tricuspid valve (TV).

The retrospective study by Burri and colleagues ${ }^{1}$ reviews 33 years of the surgical management of Ebstein anomaly (EA). The cone procedure was introduced in their center during 2010, and between 2010 and 2018 they have performed 39 cone repairs. They document the marked improvement in surgical results obtained with the cone procedure compared with other types of repairs or TV replacement (TVR), a finding echoed by most centers that have made a similar transition. They could not document improved long-term survival for cone procedure patients, although the non-cone recipients were followed for a longer period of time, which should have advantaged the cone procedure patients who had better repairs. However, this could have been a case of inferior statistical powering, and therefore we should not spend too much time on this.

The natural history of EA is that, with the exception of mild disease, life expectancy is shortened. The risk of sudden death, heart failure, and arrhythmias are substantial and increase over time. ${ }^{2-4}$ Whether early successful valve repair mitigates these risks remains unproven in a scientific sense, although it is (rightly in my opinion) accepted as fact. ${ }^{5}$ In children, there are some data showing comparable quality of life (QoL) with healthy peers. ${ }^{6}$ Given this background, it is imperative for surgeons to show that a successful EA repair will result in improved QoL and, ideally, longer life

From the Division of Cardiac, Thoracic, and Vascular Surgery, Morgan Stanley Children's Hospital and Columbia University Irving Medical Center, New York, NY. Disclosures: The author reported no conflicts of interest.

The Journal policy requires editors and reviewers to disclose conflicts of interest and to decline handling or reviewing manuscripts for which they may have a conflict of interest. The editors and reviewers of this article have no conflicts of interest.

Received for publication June 2, 2020; revisions received June 2, 2020; accepted for publication June 2, 2020; available ahead of print June 27, 2020.

Address for reprints: Emile Bacha, MD, FACS, Columbia University Irving Medical Center, 3959 Broadway, BN 276, New York, NY 10032 (E-mail: eb2709@cumc. columbia.edu).

J Thorac Cardiovasc Surg 2020;160:1554-5

$0022-5223 / \$ 36.00$

Copyright (c) 2020 by The American Association for Thoracic Surgery

https://doi.org/10.1016/j.jtcvs.2020.06.049

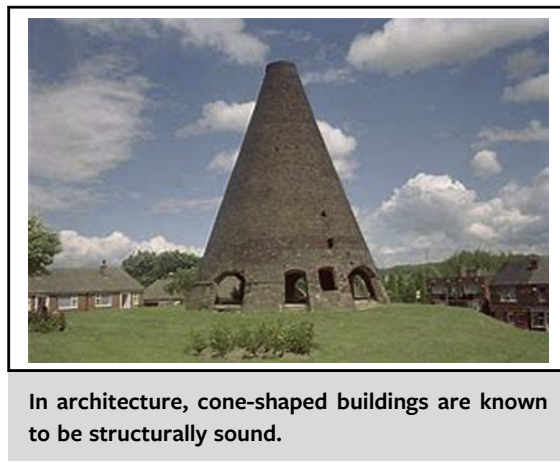

CENTRAL MESSAGE

The cone procedure has been confirmed to be superior to other repairs for Ebstein's anomaly. It is a difficult operation that is rarely done. Effect on right ventricle function and long-term survival remains unknown.

expectancy compared with medical management. This was done for the mitral valve. ${ }^{7}$ Of course, given the vastly lower incidence of EA in the general population, it will be difficult to do the same for EA surgery. A worthy substitute would be large scale use of preoperative and postoperative magnetic resonance imaging (MRI), with reporting on right ventricular function. Some centers have done this on a small scale, and this should be standardized. ${ }^{8}$ As of 2020, every EA patient should have a preoperative MRI and at least 1 midterm postoperative MRI study. An unanswered question that could be resolved with MRI studies is the degree of reduction of tricuspid regurgitation (TR) necessary to achieve improvement in right ventricular function. Is residual mild-moderate TR sufficient, or is it the absolute change from the degree of preoperative TR, which is most often wide open or severe.

Another intriguing problem is the upper age limit for a cone repair. We consider EA as a right ventricular myopathy and how an older right ventricle will react after surgery is completely unknown. I note that in this series, the 1 postoperative death after cone repair was in a 61 year-old patient who had less-than mild TR after surgery. Unpredictability in right ventricular function in older patients has also been our experience. With improvements in valve-invalve technologies, we currently favor bioprosthetic TVR in patients older than age 50 to 55 years. I was also surprised that none of the re-repairs had a cone repair. In my 
experience, the cone procedure or a variation thereof is very well suited to previously repaired TVRs because some elements (typically the detachment and clockwise rotation of the anterior leaflet) are already taken care of, and tissues are scarred and firmer.

For now, we are resigned to retrospective studies such as the present one. It provides valuable data nonetheless. The primary finding is that the cone repair is a superior technique. I suspect that before using the cone repair, surgeons in Munich were using a variation of the Carpentier, Danielson, or Sebening repair. All the pre-cone repairs were insufficient repairs in that the displaced septal leaflet was ignored, and as a consequence, there was very often moderate TR or more, and mostly emanating from the septal or anteroseptal commissure. da Silva and colleagues ${ }^{9}$ resolved this by introducing the ingenious concept of 360-degree coverage of the TV orifice with the cone construct. Having trained in the pre-cone area, and having witnessed these results, I have no doubt that the cone procedure is a more structurally sound procedure with superior long-term results. However, it is also a technically more difficult and intricate procedure with a steep learning curve. In addition, the fact that a large volume center like the Deutsches Herzzentrum in Munich only does an average of 5 cone procedures per year raises the question of whether there should be regionalization toward centers of excellence for the management of EA. ${ }^{10}$

Beyond the technical results, what a patient, especially the asymptomatic one, will want to know is whether a patient's QoL, as well as life expectancy, will be improved with surgery. As discussed above, we are unlikely to arrive at any firm data on these metrics any time soon. The best we might hope for is a registry-type multicenter study with prospective enrollment. As a community of congenital heart surgeons, this should be our goal.

\section{References}

1. Burri M, Agua KM, Cleuziou J, Beran E, Nagdyman N, Kühn A, et al. Cone versus conventional repair for Ebstein's anomaly. J Thorac Cardiovasc Surg. 2020;160:1545-53

2. Attenhofer Jost CH, Tan N, Hassan A, Vargas ER, Hodge DO, Dearani JA, et al. Sudden death in patients with Ebstein anomaly. Eur Heart J. 2018;39: 1970-7.

3. Attie F, Rosas M, Rijlaarsdam M, Buendia A, Zabal C, Kuri J, et al. The adult patient with Ebstein's anomaly. Outcome in 72 unoperated patients. Medicine (Baltimore). 2000;79:27-36.

4. Celermajer DS, Bull C, Till JA, Cullen S, Vassillikos VP, Sullivan ID, et al. Ebstein's anomaly: presentation and outcome from fetus to adult. J Am Coll Cardiol. 1994;23:170-6.

5. Tretter JT. Sudden death in Ebstein's anomaly: are we killing our patients with surgery? Eur Heart J. 2018;39:1978-80.

6. Sessions KL, Van Dorn C, Dearani JA, Warring S, Leopold K, Wackel PL, et al. Quality of life in young patients after cone reconstruction for Ebstein anomaly. Cardiol Young. 2019;29:756-60.

7. Watt TM, Brescia AA, Murray SL, Burn DA, Wisniewski A, Romano MA, et al. Degenerative mitral valve repair restores life expectancy. Ann Thorac Surg. 2020; 109:794-801.

8. Lange R, Burri M, Eschenbach LK, Badiu CC, da Silva JP, Nagdyman N, et al. Da Silva's cone repair for Ebstein's anomaly: effect on right ventricular size and function. Eur J Cardiothorac Surg. 2015;48:316-20.

9. da Silva JP, Baumgratz JF, da Fonseca L, Franchi SM, Lopes LM, Tavares GM, et al. The cone reconstruction of the tricuspid valve in Ebstein's anomaly. The operation: early and midterm results. J Thorac Cardiovasc Surg. 2007;133: 215-23.

10. Backer CL, Pasquali SK, Dearani JA. Improving national outcomes in congenita heart surgery. The time has come for regionalization of care. Circulation. 2020; 141:943-5. 